\title{
Effects of the preparation method on the structure and the visible-light photocatalytic activity of $\mathrm{Ag}_{2} \mathrm{CrO}_{4}$
}

\author{
Difa $\mathrm{Xu}^{1,2}$, Shaowen $\mathrm{Cao}^{1}$, Jinfeng Zhang ${ }^{1}$, Bei Cheng ${ }^{1}$ and Jiaguo $\mathrm{Yu}^{* 1}$
}

\section{Full Research Paper}

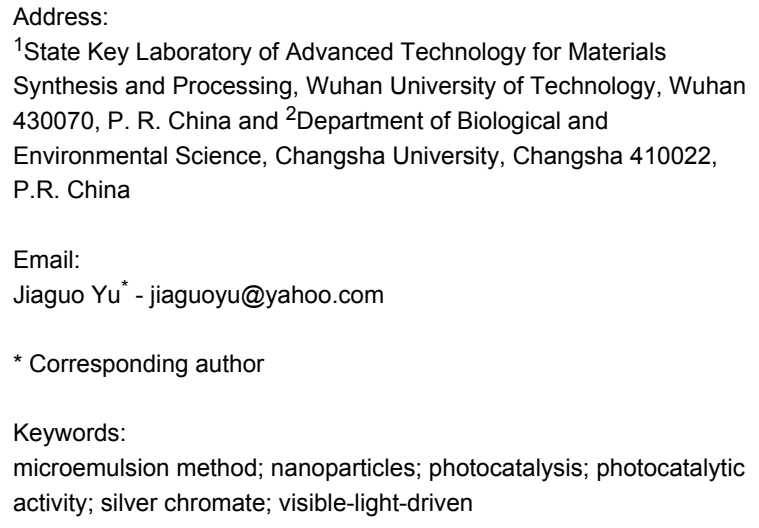

${ }^{1}$ State Key Laboratory of Advanced Technology for Materials Synthesis and Processing, Wuhan University of Technology, Wuhan 430070, P. R. China and 2Department of Biological and Environmental Science, Changsha University, Changsha 410022, P.R. China

Email:

Jiaguo Yu* - jiaguoyu@yahoo.com

* Corresponding author

Keywords:

microemulsion method; nanoparticles; photocatalysis; photocatalytic activity; silver chromate; visible-light-driven

Beilstein J. Nanotechnol. 2014, 5, 658-666. doi:10.3762/bjnano.5.77

Received: 06 January 2014

Accepted: 22 April 2014

Published: 19 May 2014

This article is part of the Thematic Series "Photocatalysis".

Guest Editor: R. Xu

(c) 2014 Xu et al; licensee Beilstein-Institut. License and terms: see end of document.

\begin{abstract}
Silver chromate $\left(\mathrm{Ag}_{2} \mathrm{CrO}_{4}\right)$ photocatalysts are prepared by microemulsion, precipitation, and hydrothermal methods, in order to investigate the effect of preparation methods on the structure and the visible-light photocatalytic activity. It is found that the photocatalytic activity of the prepared $\mathrm{Ag}_{2} \mathrm{CrO}_{4}$ was highly dependent on the preparation methods. The sample prepared by microemulsion method exhibits the highest photocatalytic efficiency on the degradation of methylene blue (MB) under visible-light irradiation. The enhanced photocatalytic activity could be ascribed to the smaller particle size, higher surface area, relatively stronger light absorption, and blue-shift absorption edge, which result in the adsorption of more MB molecules, a shorter diffusion process of more photogenerated excitons, and a stronger oxidation ability of the photogenerated holes. Considering the universalities of microemulsion, precipitation, and hydrothermal methods, this work may also provide a prototype for the comparative study of semiconductor based photocatalysis for water purification and environmental remediation.
\end{abstract}

\section{Introduction}

Semiconductor photocatalysis has been considered as a potential solution to the worldwide energy shortage and for counteracting environmental degradation [1-5]. Numerous efforts have been made to develop efficient and stable photocatalysts during the past decades. $\mathrm{TiO}_{2}$ is most widely studied because of its low cost, non-toxicity, high efficiency and long-time photostability [6-11]. However, due to its large band gap of about $3.2 \mathrm{eV}$,
$\mathrm{TiO}_{2}$ is only active in the ultraviolet (UV) region that corresponds to $3-4 \%$ of the solar light. Therefore, the development of visible-light-driven photocatalysts has received considerable attention as visible light $(400-800 \mathrm{~nm})$ is abundant in the solar spectrum [12-16]. Some semiconductors such as $\mathrm{BiVO}_{4}$ [1719], $\mathrm{Bi}_{2} \mathrm{O}_{3}$ [20,21], $\mathrm{Fe}_{2} \mathrm{O}_{3}$ [22-25], and $\mathrm{Cu}_{2} \mathrm{O}$ [26-28] have been developed as photocatalysts with visible-light activities. 
Recently, a family of Ag-based salts, including $\mathrm{Ag}_{3} \mathrm{PO}_{4}$ [29,30], $\mathrm{Ag}_{2} \mathrm{CO}_{3}[31,32], \mathrm{AgVO}_{3}[33,34], \mathrm{AgGaO}_{2}[35,36]$, has attracted particular interests due to their ability to split water, as well as decompose organic contaminants both in air and aqueous solution. However, $\mathrm{Ag}_{2} \mathrm{CrO}_{4}$ is neglected although it has been explored as cathode for lithium cells in early years [37-39]. Actually, the band gap of $\mathrm{Ag}_{2} \mathrm{CrO}_{4}$ is narrow enough (about $1.75 \mathrm{eV}$ ) to obtain strong absorption in visiblelight region [40], and thus may enable it to perform excellent visible-light photocatalytic activity. However, up to now, the photocatalytic studies on $\mathrm{Ag}_{2} \mathrm{CrO}_{4}$ are still limited with only few reports [40-42].

So far, several methods have been employed for the preparation of $\mathrm{Ag}_{2} \mathrm{CrO}_{4}$ crystals, such as precipitation [43], reversedmicellar [44], hydrothermal [45], sonochemical [41], and template methods [46]. It is known that the photocatalytic activity of semiconductor photocatalysts relies heavily on their structures, which are commonly determined by the preparation methods [47-49]. Nevertheless, to our knowledge, there is no comparative study about the effect of the preparation methods on the structure and photocatalytic performance of $\mathrm{Ag}_{2} \mathrm{CrO}_{4}$. Herein, for the first time, special attention is paid to evaluate the effect of preparation methods on the structure and visible-light photocatalytic activity of $\mathrm{Ag}_{2} \mathrm{CrO}_{4}$. Microemulsion, precipitation, and hydrothermal methods are selected for preparing $\mathrm{Ag}_{2} \mathrm{CrO}_{4}$ photocatalysts, as they are simple, efficient, and extensively used preparation methods for semiconductor crystals. In this case, the present work can also provide a prototype for comparative study of other semiconductor photocatalysts. The performance of the developed $\mathrm{Ag}_{2} \mathrm{CrO}_{4}$ is evaluated by the photocatalytic degradation of methylene blue under visible-light irradiation. The effect of the three preparation methods on the structure, optical properties and photocatalytic activity are investigated and discussed.

\section{Results and Discussion}

\section{Phase structure and morphology}

The X-ray diffraction (XRD) patterns are shown in Figure 1. All the diffraction peaks for the S-M, S-P, and S-H samples res- pectively prepared by microemulsion, precipitation, and hydrothermal methods can be indexed to the orthorhombic phase of $\mathrm{Ag}_{2} \mathrm{CrO}_{4}$ (JCPDS No. 26-0952). It is noted that the diffraction peaks of S-H sample exhibit the highest intensity (Figure 1c), resulting from the improved crystallinity of $\mathrm{Ag}_{2} \mathrm{CrO}_{4}$ promoted by hydrothermal reaction at the high temperature and pressure conditions [45]. While the crystal growth in microemulsion is restricted due to the effect of steric barrier [50,51], it is not surprising that the lowest intensity is observed for the diffraction peaks of S-M sample (Figure 1a).

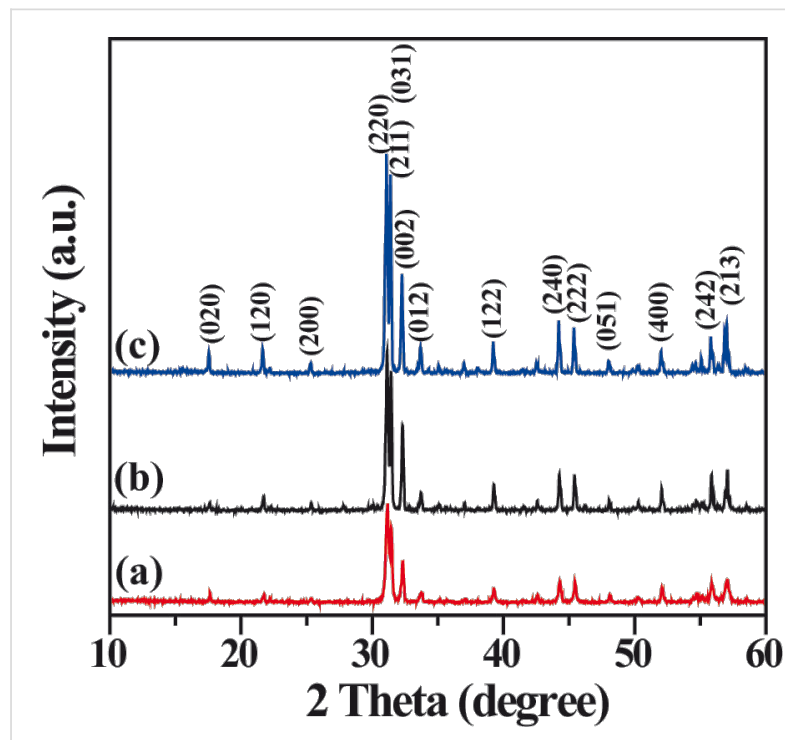

Figure 1: $\mathrm{XRD}$ patterns of $\mathrm{Ag}_{2} \mathrm{CrO}_{4}$ samples prepared by different methods: (a) microemulsion, (b) precipitation, and (c) hydrothermal.

Scanning electron microscope (SEM) images are taken to directly analyze the structure of the prepared $\mathrm{Ag}_{2} \mathrm{CrO}_{4}$ samples and particularly the effect of the preparation methods on the morphology changes. Figure 2 indicates that the S-M sample has a more homogenous morphology, and the average particle size is much smaller than those of S-P (ca. $800 \mathrm{~nm}$ ) and S-H (ca. $1.2 \mu \mathrm{m}$ ) samples. For an in-depth investigation of the morphology and particle size of the S-M sample, transmission electron microscopy (TEM) observation is carried out. As

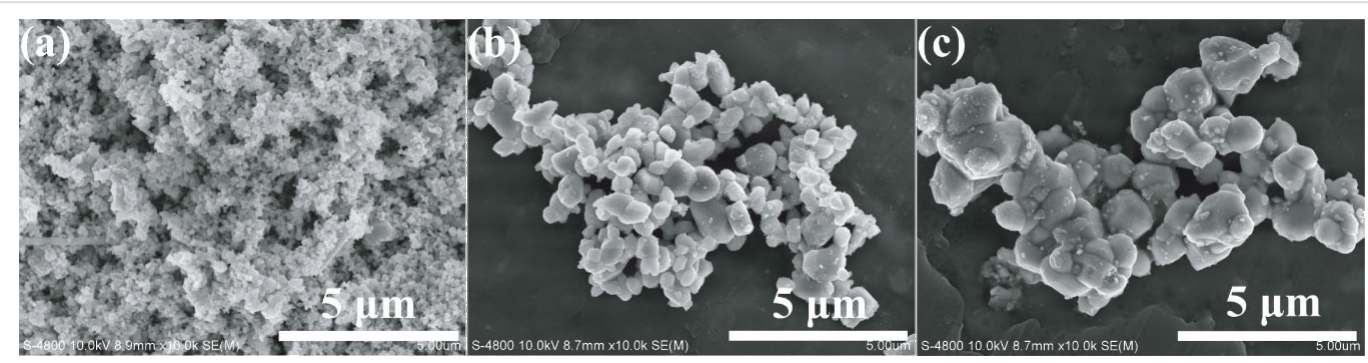

Figure 2: SEM images of $\mathrm{Ag}_{2} \mathrm{CrO}_{4}$ samples obtained from different methods: (a) microemulsion, (b) precipitation, and (c) hydrothermal. 
shown in Figure 3a, the S-M sample is composed of nanoparticles with an average particle size of about $30 \mathrm{~nm}$. The highresolution transmission electron microscopy (HRTEM) image in Figure 3b clearly shows the lattice fringes with $d$ spacings of 0.503 and $0.288 \mathrm{~nm}$, which can be assigned to the (020) and (220), respectively, crystal planes of orthorhombic $\mathrm{Ag}_{2} \mathrm{CrO}_{4}$. The corresponding fast Fourier transform (FFT) image suggests a single-crystalline nature. This also indicates that the S-M sample is well-crystallized, although its XRD pattern exhibits a relatively lower intensity (Figure $1 \mathrm{a}$ ). In our experiment, a dynamically stable and isotropic $\mathrm{W} / \mathrm{O}$ reverse microemulsion system is established by using cyclohexane as oil phase, Triton $\mathrm{X}-100$ as surfactant, and $n$-hexanol as co-surfactant, respectively. Hence a more homogeneous morphology and smaller particle size of $\mathrm{Ag}_{2} \mathrm{CrO}_{4}$ can be achieved since the precipitation reaction is restricted in nanosized water droplets, which are dispersed as liquid entities in a continuous oil media and act as nanoreactors for the synthesis of nanoparticles [52-55]. Furthermore, Triton X-100 serves as a nonionic surfactant in the W/O reverse microemulsion system to avoid the introduction of ionic impurities. These results suggest that the microemulsion method is superior for preparing $\mathrm{Ag}_{2} \mathrm{CrO}_{4}$ nanoparticles with homogenous distribution, as compared to the precipitation and hydrothermal methods.

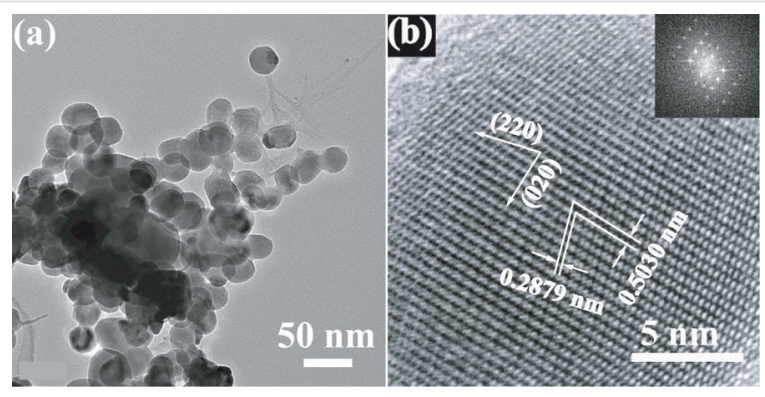

Figure 3: TEM (a) and HRTEM (b) images of $\mathrm{Ag}_{2} \mathrm{CrO}_{4}$ sample prepared by microemulsion method. The inset of $(b)$ is the corresponding FFT image.

\section{Brunauer-Emmett-Teller (BET) surface area and pore size distributions}

Figure 4 shows the nitrogen adsorption-desorption isotherms and the corresponding pore size distributions of the as-prepared $\mathrm{Ag}_{2} \mathrm{CrO}_{4}$ photocatalysts. According to the Brunauer-Deming-Deming-Teller classification, the isotherms of all $\mathrm{Ag}_{2} \mathrm{CrO}_{4}$ samples are of type IV, indicating the presence of mesopores (2-50 nm) [56-58]. Moreover, the shapes of the hysteresis loops are of type $\mathrm{H} 3$ at the high relative pressure range from 0.8 to 1.0 , which suggests the formation of large mesopores and macropores [56]. The pore size distributions (inset of Figure 4) are very broad, further confirming the presence of large mesopores and macropores. Considering the absence of a pore structure inside the individual nanoparticles on the basis of SEM and TEM results, these pores can be related to the pores between the aggregated $\mathrm{Ag}_{2} \mathrm{CrO}_{4}$ particles. The $\mathrm{Ag}_{2} \mathrm{CrO}_{4}$ samples show decreasing specific surface areas in the sequence S-M, S-P, and S-H, which are listed in Table 1. This is because the S-M sample has the smallest particle size, whereas the S-H sample has the largest particle size. Usually, photocatalysts with higher specific surface areas are beneficial for the enhancement of photocatalytic performance by facilitating the absorption of pollutants for degradation.

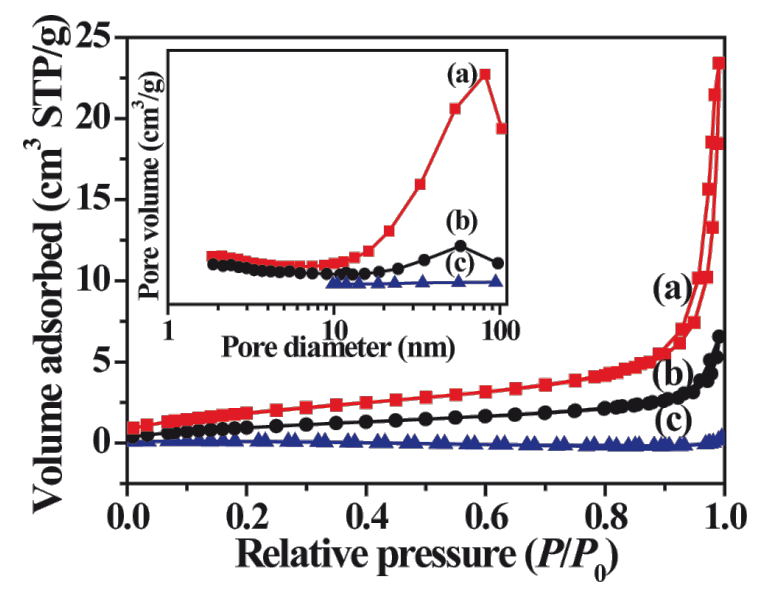

Figure 4: Nitrogen adsorption-desorption isotherms and corresponding pore size distribution curves (inset) of $\mathrm{Ag}_{2} \mathrm{CrO}_{4}$ samples prepared by different methods: (a) microemulsion, (b) precipitation, and (c) hydrothermal.

\section{UV-vis spectroscopy measurements}

A comparison of UV-vis diffuse reflectance spectra (DRS) and the corresponding colours of the $\mathrm{Ag}_{2} \mathrm{CrO}_{4}$ samples are

\begin{tabular}{|llllll}
\hline \multicolumn{2}{l}{ Table 1: Physical properties and photocatalytic performance of as-prepared samples. } & & \\
sample & preparation method & particle size $(\mathrm{nm})$ & $\mathrm{S}_{\mathrm{BET}}{ }^{\mathrm{a}}\left(\mathrm{m}^{2} / \mathrm{g}\right)$ & band gap $(\mathrm{eV})$ & rate constant $k\left(\mathrm{~min}^{-1}\right)$ \\
\hline S-M & microemulsion & 30 & 7.0 & 1.85 & 0.033 \\
S-P & precipitation & 800 & 4.0 & 1.82 & 0.020 \\
S-H & hydrothermal & 1200 & 0.3 & 1.76 & 0.015 \\
\hline
\end{tabular}

${ }^{a} B E T$ specific surface area. 
displayed in Figure 5. An enhanced absorption of visible light in the range of 400-600 $\mathrm{nm}$ and 700-900 $\mathrm{nm}$ can be observed for the S-M sample (Figure 5a), as compared to that for the S-P sample (Figure 5c), which may be attributed to the increased intensity of the scattered light in the sample with smaller particle size [59]. Moreover, there is an obvious blue shift of the absorption edge for the S-M sample, which should be explained in terms of the small size effect $[60,61]$. In contrast, a weaker light absorption and red shift of the absorption edge are observed for the S-H sample (Figure 5b), because it has the largest particle size among the three samples. The indirect band gaps of the $\mathrm{Ag}_{2} \mathrm{CrO}_{4}$ samples are calculated according to the Kubelka-Munk (KM) method by the following equation [62]:

$$
\alpha h v=\mathrm{A}\left(h v-E_{\mathrm{g}}\right)^{2}
$$

where $\alpha$ is the absorption coefficient, $h v$ is the photon energy, $E_{\mathrm{g}}$ is the indirect band gap, and $\mathrm{A}$ is a constant. As shown in the inset of Figure 5, the calculated band gap energies of the S-M, $\mathrm{S}-\mathrm{P}$ and S-H samples are $1.85,1.82$ and $1.76 \mathrm{eV}$, respectively (Table 1). In spite of the little difference of the band gaps, it is clear that all the three $\mathrm{Ag}_{2} \mathrm{CrO}_{4}$ samples exhibit an excellent visible-light response for photocatalytic applications.

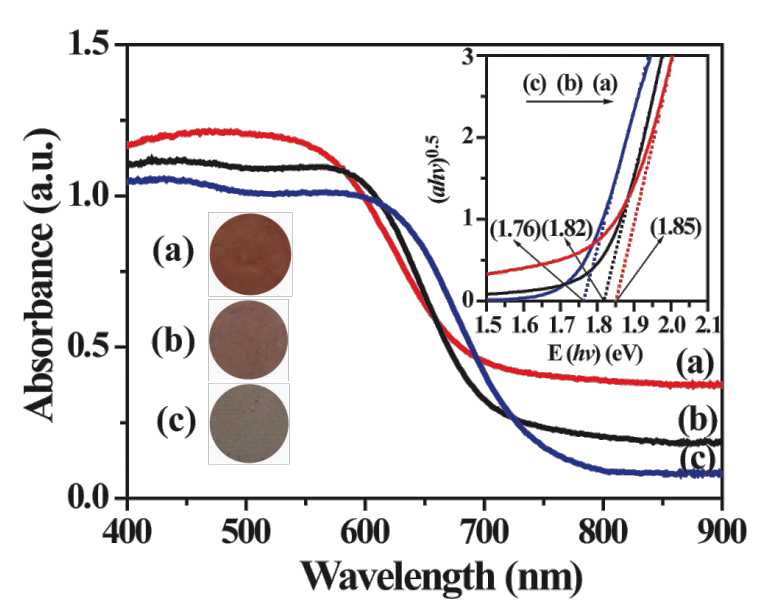

Figure 5: UV-visible diffuse reflectance spectra, the calculated band gaps (upper right inset) and the corresponding colours (lower left inset) of $\mathrm{Ag}_{2} \mathrm{CrO}_{4}$ samples prepared by different methods: (a) microemulsion, (b) precipitation, and (c) hydrothermal.

\section{Calculation}

Theoretically, the band structure of the $\mathrm{Ag}_{2} \mathrm{CrO}_{4}$ is also calculated by density function theory (DFT) (Figure 6). As shown in the band structure plots, the calculated band gap energy of $\mathrm{Ag}_{2} \mathrm{CrO}_{4}$ is $1.37 \mathrm{eV}$, which is lower than the experimental values, which is due to the well-known limitation of DFT calculation $[63,64]$. The electronic structure of $\mathrm{Ag}_{2} \mathrm{CrO}_{4}$ indicates that the valence band mainly consists of occupied Ag $4 \mathrm{~d}$ and O $2 p$ orbitals, and the conduction band mainly comes from the empty $\mathrm{Cr} 3 \mathrm{~d}$ orbital, which means that $\mathrm{Cr}$ makes an important contribution to the bottom of the conduction band. It has been found that $\mathrm{Ag}$ is one of the elements that are able to form a valence band position higher than the $\mathrm{O} 2 \mathrm{p}$ orbital [65]. It has been demonstrated that $\mathrm{Cr}$ has the potential ability to lower down the bottom of the conduction band $[40,66]$. Thereby the synergistic effect of $\mathrm{Ag}$ and $\mathrm{Cr}$ elements results in the narrow band gap of $\mathrm{Ag}_{2} \mathrm{CrO}_{4}$. The calculated results also show that the top of the valence band is at the $G$ point but the bottom of the conduction band is near the $\mathrm{Z}$ point, which confirms that $\mathrm{Ag}_{2} \mathrm{CrO}_{4}$ has an indirect band gap structure. These results indicate that $\mathrm{Ag}_{2} \mathrm{CrO}_{4}$ can potentially serve as a visible-light-driven photocatalyst.

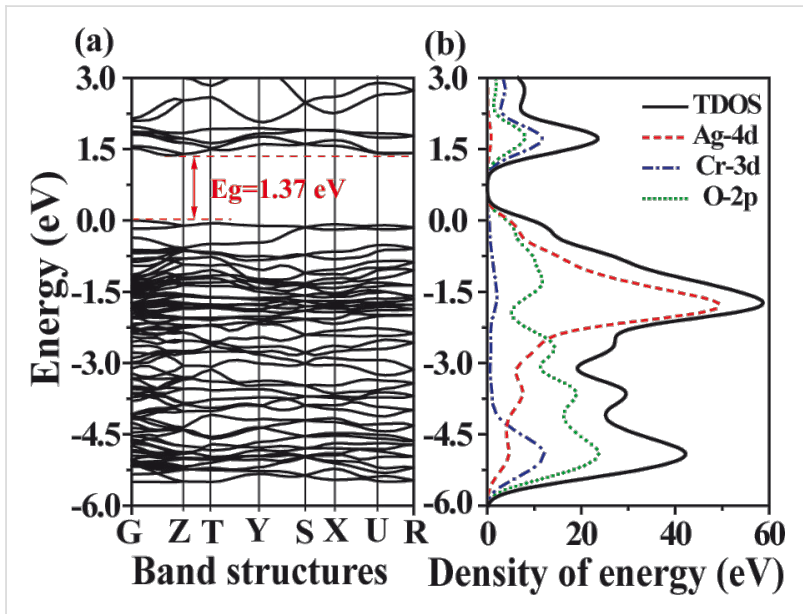

Figure 6: Band structure plots (a) and density of states (b) for $\mathrm{Ag}_{2} \mathrm{CrO}_{4}$.

\section{Photocatalytic activity}

We have measured the zeta potential of $\mathrm{Ag}_{2} \mathrm{CrO}_{4}$ as $-15.8 \mathrm{mV}$ at $\mathrm{pH} 6.8$, suggesting that it is electronegative in neutral solutions. Since $\mathrm{MB}$ is a cationic dye, it can be easily adsorbed on the surface of $\mathrm{Ag}_{2} \mathrm{CrO}_{4}$ through electrostatic interaction. Therefore, the photocatalytic activity of the as-prepared $\mathrm{Ag}_{2} \mathrm{CrO}_{4}$ samples is evaluated through MB degradation under visiblelight irradiation. Without any photocatalyst, no obvious MB degradation is observed under visible-light irradiation. For comparison, P25 (commercial $\mathrm{TiO}_{2}$, Degussa, Germany) is also used as a reference. Figure 7 shows that all $\mathrm{Ag}_{2} \mathrm{CrO}_{4}$ samples exhibit a much better photocatalytic performance than $\mathrm{P} 25$ in the $\mathrm{MB}$ degradation. In particular, the $\mathrm{S}-\mathrm{M} \mathrm{Ag}_{2} \mathrm{CrO}_{4}$ sample shows the highest activity with a rate constant of $0.033 \mathrm{~min}^{-1}$, and MB is almost completely degraded within $90 \mathrm{~min}$. The S-P and $\mathrm{S}-\mathrm{H}$ samples exhibit a lower activity with rate constants of 0.020 and $0.012 \mathrm{~min}^{-1}$, respectively. $\mathrm{P} 25$ is a mixed-phase $\mathrm{TiO}_{2}$ containing $25 \%$ rutile, whit a band gap of $3.0 \mathrm{eV}$, which results 
in a weak visible-light absorption up to about $413 \mathrm{~nm}$. Therefore, P25 still shows some photocatalytic activity under visiblelight irradiation. But it is not surprising that the rate constant for P25 is only $0.007 \mathrm{~min}^{-1}$ because the other phase anatase (75\%) is not active in the visible region.

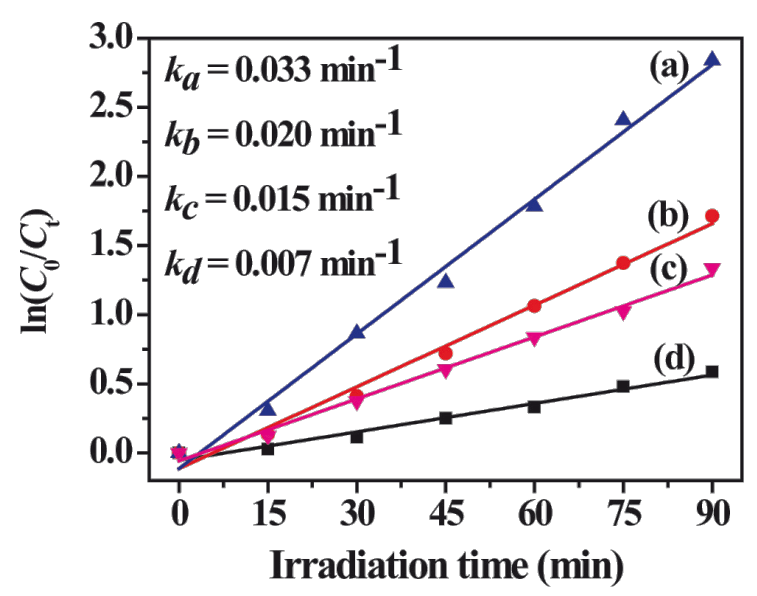

Figure 7: Photocatalytic degradation of $\mathrm{MB}$ aqueous solution over $\mathrm{Ag}_{2} \mathrm{CrO}_{4}$ samples prepared by (a) microemulsion, (b) precipitation, and (c) hydrothermal methods, and (d) P25 sample under visible-light irradiation.

Generally, the photocatalytic degradation of dyes in water is mainly attributed to the photogenerated holes, and the active oxygen species, including superoxide radicals $\left(\mathrm{O}_{2}{ }^{--}\right)$and hydroxyl radicals $\left(\mathrm{OH}^{*}\right)$. In order to understand the possible mechanism of the photocatalytic degradation of $\mathrm{MB}$ over $\mathrm{Ag}_{2} \mathrm{CrO}_{4}$, we have determined the $\mathrm{CB}$ and $\mathrm{VB}$ position at the point of zero charge by a widely accepted approach based on the following equation $[67,68]$ :

$$
E_{\mathrm{CB}}=\chi-E^{\mathrm{C}}-0.5 E_{\mathrm{g}}
$$

where $E_{\mathrm{CB}}$ is the $\mathrm{CB}$ edge potential, $\chi$ is the absolute electronegativity of the semiconductor. $E^{\mathrm{C}}$ is the energy of free electrons on the hydrogen scale (ca. $4.5 \mathrm{eV}$ ), and $E_{\mathrm{g}}$ is the band gap of the semiconductor. Accordingly, the $\mathrm{CB}$ energy level of $\mathrm{Ag}_{2} \mathrm{CrO}_{4}$ is calculated to be ca. $0.46 \mathrm{eV}$ (vs NHE), which is less negative than the $\mathrm{O}_{2} / \mathrm{O}_{2}{ }^{--}$potential; and the $\mathrm{VB}$ energy level of $\mathrm{Ag}_{2} \mathrm{CrO}_{4}$ is calculated to be ca. $2.26 \mathrm{eV}$ (vs NHE), which is less positive than $\mathrm{OH}^{*} / \mathrm{OH}^{-}$potential [69]. As a result, the photogenerated electrons on the $\mathrm{CB}$ of $\mathrm{Ag}_{2} \mathrm{CrO}_{4}$ are not able to reduce the adsorbed $\mathrm{O}_{2}$ to yield $\mathrm{O}_{2}{ }^{\cdot-}$, meanwhile the photogenerated holes on the $\mathrm{VB}$ of $\mathrm{Ag}_{2} \mathrm{CrO}_{4}$ also can not oxidize $\mathrm{H}_{2} \mathrm{O}$ to form $\mathrm{OH}^{\bullet}$ due to their insufficient reduction (for electron) and oxidation ability (for hole). In addition, the energy level of the lowest unoccupied molecular orbital (LUMO) and the highest occupied molecular orbital (HOMO) of MB are reported as ca. -0.25 and $1.6 \mathrm{eV}[70,71]$, respectively. As such, the direct decomposition of $\mathrm{MB}$ molecules by the photogenerated holes on the $\mathrm{VB}$ of $\mathrm{Ag}_{2} \mathrm{CrO}_{4}$ is expected, since the $\mathrm{VB}$ of $\mathrm{Ag}_{2} \mathrm{CrO}_{4}$ is more positive than the HOMO of MB. Therefore, we assume that the main active species for the photocatalytic degradation of $\mathrm{MB}$ over $\mathrm{Ag}_{2} \mathrm{CrO}_{4}$ should be photogenerated holes.

The highest photocatalytic efficiency for the S-M sample is attributed to several major factors. First, the S-M sample has the highest surface area. Its photocatalytic efficiency is improved by adsorbing more MB molecules for a more efficient interaction between $\mathrm{MB}$ and $\mathrm{Ag}_{2} \mathrm{CrO}_{4}$. Second, the smaller particle size of the S-M sample can shorten the diffusion process of photogenerated electrons and holes to the surface of $\mathrm{Ag}_{2} \mathrm{CrO}_{4}$, thus reducing the rate of recombination [72]. Third, the enhanced visible-light absorption in the range of 400-600 nm for the S-M sample (Figure 5) can allow for a more efficient utilization of the solar energy to generate more electrons and holes and to further promote the catalytic process. Finally, the relatively wider band gap, compared to those of the S-P and $\mathrm{S}-\mathrm{H}$ samples, calculated from the obvious blue-shift absorption edge of the S-M sample (Figure 5) can lead to a higher redox potential, thereby resulting in a stronger oxidation ability of the photogenerated holes $[73,74]$. Overall the results suggest that the photocatalytic efficiency of the $\mathrm{Ag}_{2} \mathrm{CrO}_{4}$ samples is influenced by the surface area, particle size and optical property, which originate from the different structure caused by different preparation methods.

We further explore the photocatalytic stability of the S-M $\mathrm{Ag}_{2} \mathrm{CrO}_{4}$ sample by a cycling test of photocatalytic degradation of a MB aqueous solution under visible-light irradi-

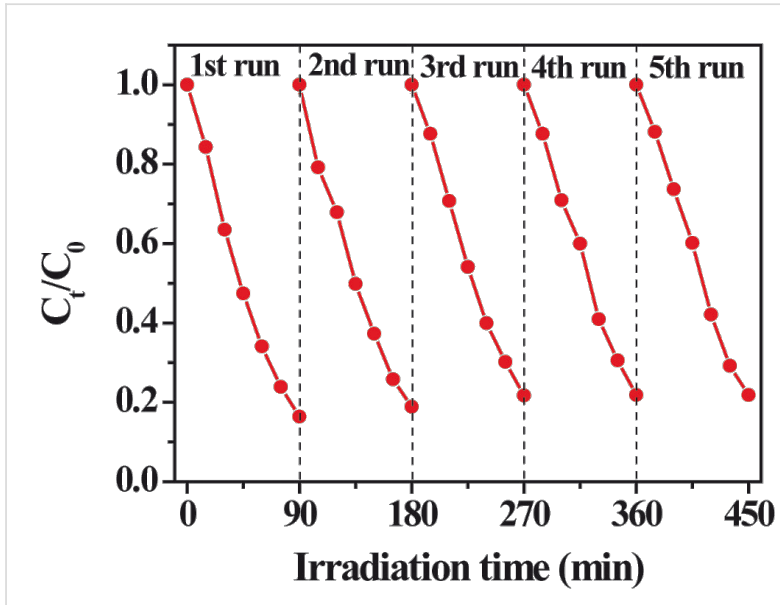

Figure 8: Cycling test of the photocatalytic degradation under visiblelight irradiation of a MB aqueous solution in the presence of the $\mathrm{Ag}_{2} \mathrm{CrO}_{4}$ sample prepared by microemulsion method. 
ation. Figure 8 reveals that no obvious decrease of the photocatalytic activity was observed after five cycles, suggesting the excellent photocatalytic stability of the S-M $\mathrm{Ag}_{2} \mathrm{CrO}_{4}$ sample in the reactions.

To investigate the structure of $\mathrm{Ag}_{2} \mathrm{CrO}_{4}$ after five circles of the photocatalytic reaction, the corresponding SEM and TEM images, XRD pattern, and UV-vis diffuse reflectance spectrum were collected. Figure 9a and Figure $9 \mathrm{~b}$ show that the overall morphology and average particle size of $\mathrm{Ag}_{2} \mathrm{CrO}_{4}$ were not changed significantly. However, some homogenously distributed $\mathrm{Ag}$ nanoparticles could be observed on the surface of $\mathrm{Ag}_{2} \mathrm{CrO}_{4}$ (Figure 9b). The existence of metallic Ag could be further demonstrated by the XRD pattern (Figure 9c), which displayed a new peak located at $2 \theta=38.1^{\circ}$ corresponding to the (111) plane of silver (JCPDS No. 65-2871). The UV-visible spectrum with the corresponding colour of $\mathrm{Ag}_{2} \mathrm{CrO}_{4}$ after five circles of photocatalytic reaction is displayed in Figure 9d. It was found that the absorbance intensity in the visible-light region largely increased, which could be ascribed to the darkened colour of $\mathrm{Ag}_{2} \mathrm{CrO}_{4}$ after photocatalysis, resulting from the silver nanoparticles [32]. These results indicate that $\mathrm{Ag}_{2} \mathrm{CrO}_{4}$ was partially reduced to metallic $\mathrm{Ag}$ and formed an $\mathrm{Ag}-\mathrm{Ag}_{2} \mathrm{CrO}_{4}$ composite. However, the majority of $\mathrm{Ag}_{2} \mathrm{CrO}_{4}$ was still preserved, and the formed $\mathrm{Ag}$ particles may further promote the photocatalytic activity in terms of surface plasmon resonance [75,76] and electron-sink effect [30]. Therefore, the photocatalytic activity of $\mathrm{Ag}_{2} \mathrm{CrO}_{4}$ did not show obvious decrease after 5 -circle reaction.
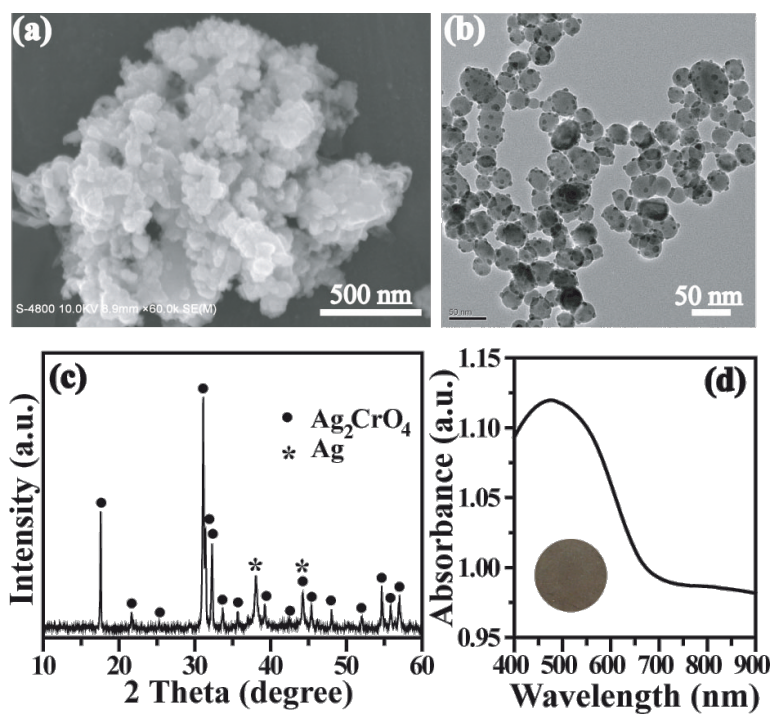

Figure 9: (a) SEM image, (b) TEM image, (c) XRD pattern, and (d) UV-visible spectrum of $\mathrm{Ag}_{2} \mathrm{CrO}_{4}$ after five circles of photocatalytic reaction.

\section{Conclusion}

In summary, a range of $\mathrm{Ag}_{2} \mathrm{CrO}_{4}$ photocatalysts are prepared by microemulsion, precipitation, and hydrothermal methods. The preparation methods exhibit a great influence on the structure, optical properties and photocatalytic activity of the $\mathrm{Ag}_{2} \mathrm{CrO}_{4}$ crystals. The sample prepared by microemulsion method has the smallest particle size, highest surface area, most efficient light absorption, and a blue-shifted absorption edge. Consequently, the microemulsion prepared $\mathrm{Ag}_{2} \mathrm{CrO}_{4}$ photocatalyst shows the best activity in the photodegradation of a $\mathrm{MB}$ aqueous solution, because of the higher adsorption of MB molecules, shorter diffusion process of more photogenerated excitons, and stronger oxidation ability of the photogenerated holes. The current investigation may provide new insight into the effect of preparation methods on the structure and photocatalytic activity of photocatalysts. Future work may focus on the study of the visible-light photocatalytic mechanism and the stability promoting methods of $\mathrm{Ag}_{2} \mathrm{CrO}_{4}$. Moreover, it is also possible to investigate the photocatalytic activity of $\mathrm{Ag}_{2} \mathrm{CrO}_{4}$ toward the degradation of other organic pollutants under visible-light irradiation.

\section{Experimental \\ Preparation of $\mathrm{Ag}_{2} \mathrm{CrO}_{4}$ photocatalysts}

All chemicals were analytical grade and used without further purification. Deionized (DI) water was used in all experiments. The $\mathrm{Ag}_{2} \mathrm{CrO}_{4}$ photocatalysts were prepared by the microemulsion, precipitation, and hydrothermal methods. The corresponding samples were labeled as S-M, S-P and S-H, respectively, as listed in Table 1. The detailed experimental procedures for the preparation of the samples are described as follows:

Sample S-M: Under stirring, cyclohexane (16 mL), Triton $\mathrm{X}-100(5.2 \mathrm{~mL})$ and $n$-hexanol $(3 \mathrm{~mL})$ were mixed at room temperature. Then $\mathrm{K}_{2} \mathrm{CrO}_{4}$ aqueous solution $(0.5 \mathrm{~mL}, 0.5 \mathrm{M})$ was dripped into the mixture under continuous stirring to form a clarified and transparent $\mathrm{W} / \mathrm{O}$ reversed-micellar solution, followed by the dropwise addition of $\mathrm{AgNO}_{3}$ aqueous solution $(0.5 \mathrm{~mL}, 0.25 \mathrm{M})$ and kept for $1 \mathrm{~h}$ under stirring. The resultant suspension was aged for $24 \mathrm{~h}$.

Sample S-P: $\mathrm{AgNO}_{3}(1000 \mathrm{~mL}, 0.5 \mathrm{M})$ and $\mathrm{K}_{2} \mathrm{CrO}_{4}(1000 \mathrm{~mL}$, $0.25 \mathrm{M}$ ) aqueous solutions were mixed together under vigorous stirring. The resultant suspension was then aged for $24 \mathrm{~h}$.

Sample S-H: The sample prepared by precipitation method was loaded into a Teflon-lined stainless steel autoclave with a capacity of $100 \mathrm{~mL}$, sealed, heated to and maintained at $160{ }^{\circ} \mathrm{C}$ for $16 \mathrm{~h}$, and subsequently cooled to room temperature naturally. 
All the samples were collected and washed by centrifugation-redispersion cycles with ethanol and water, and then dried at $70{ }^{\circ} \mathrm{C}$ for $4 \mathrm{~h}$.

\section{Characterization}

The XRD were recorded on an X-ray diffractometer (type

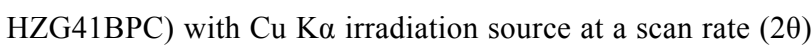
of $0.05^{\circ} \cdot \mathrm{s}^{-1}$. The accelerating voltage and applied current were $40 \mathrm{kV}$ and $80 \mathrm{~mA}$, respectively. The morphology observation was carried out by SEM (S4800, Hitachi, Japan) at an accelerating voltage of $5 \mathrm{kV}$. TEM and HRTEM analysis were conducted by the transmission electron microscopy (JEM$2100 \mathrm{~F}$, JEOL, Japan) at an accelerating voltage of $200 \mathrm{kV}$. The DRS were taken with a UV-vis spectrophotometer (UV2550, Shimadzu, Japan). $\mathrm{BaSO}_{4}$ was used as a reflectance standard. The nitrogen adsorption and desorption isotherms were measured by using an ASAP 2020 system (Micromertitics instruments, USA) after the samples were degassed at $180^{\circ} \mathrm{C}$. The $S_{\mathrm{BET}}$ was determined by a multipoint BET method using the adsorption data in the relative pressure $\left(P / P_{0}\right)$ range of $0.05-0.3$. The desorption data was used to determine the pore size distribution through the Barret-Joyner-Halenda (BJH) method. The nitrogen adsorption volume at $P / P_{0}$ of 0.994 was used to determine the average pore size. Zeta potential was measured by electrophoretic light scattering with a zetasizer (Nano ZS90, Malvern, UK).

\section{Computational details}

The DFT calculations were carried out to investigate the band structure and density of states (DOS) of $\mathrm{Ag}_{2} \mathrm{CrO}_{4}$ model by using the CASTEP Packages on the basis of the plane-wavepseudo-potential approach $[77,78]$. Combined with ultrasoft pseudo-potentials, the Perdew-Burke-Ernzerhof (PBE) of generalized gradient approximation (GGA) was applied as the exchange-correlation function $[79,80]$. The plane-wave cut-off energy was set to be $500 \mathrm{eV}$, the Monkhorst-Pack $k$-point in the Brilliouin Zone to be $3 \times 5 \times 6$, and the self-consistent field (SCF) convergence accuracy to be $1 \times 10^{-6} \mathrm{eV} /$ atom. For the geometric optimization, the convergence criteria were set as follows: $1 \times 10^{-5} \mathrm{eV} /$ atom for total energy, $0.03 \mathrm{eV} / \AA$ for maximum force, $0.05 \mathrm{GPa}$ for maximum stress, and $1 \times 10^{-3} \AA$ for maximum displacement. The energy and geometry structure showed no obvious change when higher cut-off energy and more $k$-points were adopted. The electronic structure calculation was carried out by using the optimized geometric structure.

\section{Measurements of photocatalytic activity}

The photocatalytic activity of the as-prepared samples was evaluated by the photocatalytic degradation of MB under visiblelight irradiation in water at ambient temperature. The prepared photocatalysts $(50 \mathrm{mg})$ were firstly dispersed into water in a reactor with a diameter of $7.0 \mathrm{~cm}$ and then dried at $80{ }^{\circ} \mathrm{C}$ for $4 \mathrm{~h}$, giving rise to the formation of $\mathrm{Ag}_{2} \mathrm{CrO}_{4}$ films at the bottom of the reactor. $\mathrm{MB}$ aqueous solution $\left(50 \mathrm{~mL}, 2.5 \times 10^{-5} \mathrm{M}\right)$ was added into the reactor and kept in the dark for $30 \mathrm{~min}$ to ensure an adsorption-desorption equilibrium prior to irradiation. A $300 \mathrm{~W}$ xenon arc lamp coupled with a UV cut-off filter $(\lambda \geq 400 \mathrm{~nm})$, which was positioned $20 \mathrm{~cm}$ away from the reactor, was used as a visible-light source to drive the photocatalytic reaction. The concentration of MB was determined by a UV-vis spectrophotometer (UV2550, Shimadzu, Japan). After irradiation for every $15 \mathrm{~min}$, the reaction solution was taken out to measure the concentration change of MB. As for the MB aqueous solution with low concentration, its photocatalytic degradation was a pseudo-fist-order reaction and its kinetics was expressed as [81-83]:

$$
\ln \left(C_{0} / C_{\mathrm{t}}\right)=k \cdot t
$$

Where $k$ is the apparent rate constant, $C_{0}$ and $C_{\mathrm{t}}$ are the initial and reaction concentrations of $\mathrm{MB}$, respectively.

\section{Acknowledgements}

This work was supported by the 973 program (2013CB632402), 863 Program (2012AA062701), and NSFC (51272199, 51320105001, 51372190 and 21177100). Also, this work was financially supported by the Fundamental Research Funds for the Central Universities (2013-VII-030) and Self-determined and Innovative Research Funds of SKLWUT (2013-ZD-1).

\section{References}

1. Xiang, Q.; Yu, J. J. Phys. Chem. Lett. 2013, 4, 753-759. doi:10.1021/jz302048d

2. Kudo, A.; Miseki, Y. Chem. Soc. Rev. 2009, 38, 253-278. doi:10.1039/b800489g

3. Jin, J.; Yu, J.; Liu, G.; Wong, P. K. J. Mater. Chem. A 2013, 1, 10927-10934. doi:10.1039/c3ta12301d

4. Tong, H.; Ouyang, S.; Bi, Y.; Umezawa, N.; Oshikiri, M.; Ye, J. Adv. Mater. 2012, 24, 229-251. doi:10.1002/adma.201102752

5. Xiang, Q.; Yu, J.; Jaroniec, M. Chem. Soc. Rev. 2012, 41, 782-796. doi:10.1039/c1cs15172j

6. Linsebigler, A. L.; Lu, G.; Yates, J. T. Chem. Rev. 1995, 95, 735-758. doi:10.1021/cr00035a013

7. Wen, C. Z.; Zhou, J. Z.; Jiang, H. B.; Hu, Q. H.; Qiao, S. Z.; Yang, H. G. Chem. Commun. 2011, 47, 4400-4402. doi:10.1039/c0cc05798c

8. Yu, J.; Wang, Y.; Xiao, W. J. Mater. Chem. A 2013, 1, 10727-10735. doi:10.1039/c3ta12218b

9. Chatterjee, D.; Dasgupta, S. J. Photochem. Photobiol., C 2005, 6, 186-205. doi:10.1016/j.jphotochemrev.2005.09.001

10. Mitsionis, A.; Vaimakis, T.; Trapalis, C.; Todorova, N.; Bahnemann, D.; Dillert, R. Appl. Catal., B 2011, 106, 398-404. doi:10.1016/j.apcatb.2011.05.047 
11. Hernández-Alonso, M. D.; Fresno, F.; Suárez, S.; Coronado, J. M. Energy Environ. Sci. 2009, 2, 1231-1257. doi:10.1039/b907933e

12. Yang, X.; Cao, C. D.; Erickson, L.; Hohn, K.; Maghirang, R.; Klabunde, K. Appl. Catal., B 2009, 91, 657-662. doi:10.1016/j.apcatb.2009.07.006

13. Asahi, R.; Morikawa, T.; Ohwaki, T.; Aoki, K.; Taga, Y. Science 2001, 293, 269-271. doi:10.1126/science.1061051

14. Low, J.; Yu, J.; Li, Q.; Cheng, B. Phys. Chem. Chem. Phys. 2014, 16, 1111-1120. doi:10.1039/c3cp53820f

15. Yu, J.; Zhou, P.; Li, Q. Phys. Chem. Chem. Phys. 2013, 15, 12040-12047. doi:10.1039/c3cp44651d

16. Yu, J.; Wang, S.; Low, J.; Xiao, W. Phys. Chem. Chem. Phys. 2013, 15, 16883-16890. doi:10.1039/c3cp53131g

17. Li, R.; Zhang, F.; Wang, D.; Yang, J.; Li, M.; Zhu, J.; Zhou, X.; Han, H.; Li, C. Nat. Commun. 2013, 4, No. 1432. doi:10.1038/ncomms2401

18. Cao, S.-W.; Yin, Z.; Barber, J.; Boey, F. Y. C.; Loo, S. C. J.; Xue, C. ACS Appl. Mater. Interfaces 2012, 4, 418-423. doi:10.1021/am201481b

19. Puttaswamy, M.; Ran, J.; Zhang, J.; Yu, J.; Liu, G. Appl. Catal., B: Environ. 2011, 110, 286-295. doi:10.1016/j.apcatb.2011.09.014

20. Liu, H.; Luo, M.; Hu, J.; Zhou, T.; Chen, R.; Li, J. Appl. Catal., B: Environ. 2013, 140-141, 141-150. doi:10.1016/j.apcatb.2013.04.009

21. Hu, J.; Li, H.; Huang, C.; Liu, M.; Qiu, X. Appl. Catal., B: Environ. 2013, 142-143, 598-603. doi:10.1016/j.apcatb.2013.05.079

22. Qu, J.; Yu, Y.; Cao, C.-Y.; Song, W.-G. Chem.-Eur. J. 2013, 19, 11172-11177. doi:10.1002/chem.201301295

23. Yu, J.; Yu, X.; Huang, B.; Zhang, X.; Dai, Y. Cryst. Growth Des. 2009, 9, 1474-1480. doi:10.1021/cg800941d

24. Zhou, X.; Xu, Q.; Lei, W.; Zhang, T.; Qi, X.; Liu, G.; Deng, K.; Yu, J. Small 2014, 10, 674-679. doi:10.1002/smll.201370001

25. Sun, W.; Meng, Q.; Jing, L.; Liu, D.; Cao, Y. J. Phys. Chem. C 2013, 117, 1358-1365. doi:10.1021/jp309599d

26. Huang, W.-C.; Lyu, L.-M.; Yang, Y.-C.; Huang, M. H. J. Am. Chem. Soc. 2012, 134, 1261-1267. doi:10.1021/ja209662v

27. Yu, H.; Yu, J.; Liu, S.; Mann, S. Chem. Mater. 2007, 19, 4327-4334. doi:10.1021/cm070386d

28. Li, J.; Cushing, S. K.; Bright, J.; Meng, F.; Senty, T. R.; Zheng, P.; Bristow, A. D.; Wu, N. ACS Catal. 2013, 3, 47-51. doi:10.1021/cs300672f

29. Yi, Z.; Ye, J.; Kikugawa, N.; Kako, T.; Ouyang, S.; Stuart-Williams, H.; Yang, H.; Cao, J.; Luo, W.; Li, Z.; Liu, Y.; Withers, R. L. Nat. Mater. 2010, 9, 559-564. doi:10.1038/nmat2780

30. Wang, W.; Cheng, B.; Yu, J.; Liu, G.; Fan, W. Chem.-Asian J. 2012, 7, 1902-1908. doi:10.1002/asia.201200197

31. Xu, C.; Liu, Y.; Huang, B.; Li, H.; Qin, X.; Zhang, X.; Dai, Y. Appl. Surf. Sci. 2011, 257, 8732-8736. doi:10.1016/j.apsusc.2011.05.060

32. Dai, G.; Yu, J.; Liu, G. J. Phys. Chem. C 2012, 116, 15519-15524. doi:10.1021/jp305669f

33. Ju, P.; Fan, H.; Zhang, B.; Shang, K.; Liu, T.; Ai, S.; Zhang, D. Sep. Purif. Technol. 2013, 109, 107-110. doi:10.1016/j.seppur.2013.01.057

34. Xu, J.; Hu, C.; Xi, Y.; Wan, B.; Zhang, C.; Zhang, Y. Solid State Sci. 2012, 14, 535-539. doi:10.1016/j.solidstatesciences.2012.01.013

35. Dong, H.; Li, Z.; Xu, X.; Ding, Z.; Wu, L.; Wang, X.; Fu, X. Appl. Catal., B: Environ. 2009, 89, 551-556. doi:10.1016/j.apcatb.2009.01.018
36. Maruyama, Y.; Irie, H.; Hashimoto, K. J. Phys. Chem. B 2006, 110, 23274-23278. doi:10.1021/jp063406s

37. Eichinger, G.; Besenhard, J. O.

J. Electroanal. Chem. Interfacial Electrochem. 1976, 72, 1-31. doi:10.1016/S0022-0728(76)80072-1

38. Cignini, P. J. Power Sources 1978, 3, 347-357. doi:10.1016/0378-7753(78)80023-8

39. Messina, R.; Perichon, J. J. Electroanal. Chem. Interfacial Electrochem. 1982, 133, 115-123. doi:10.1016/0022-0728(82)87010-1

40. Ouyang, S.; Li, Z.; Ouyang, Z.; Yu, T.; Ye, J.; Zou, Z. J. Phys. Chem. C 2008, 112, 3134-3141. doi:10.1021/jp077127w

41. Soofivand, F.; Mohandes, F.; Salavati-Niasari, M. Mater. Res. Bull. 2013, 48, 2084-2094. doi:10.1016/j.materresbull.2013.02.025

42. Liu, Y.; Yu, H.; Cai, M.; Sun, J. Catal. Commun. 2012, 26, 63-67. doi:10.1016/j.catcom.2012.04.017

43. Alamdari, R. F.; Hajimirsadeghi, S. S.; Kohsari, I. Inorg. Mater. 2010, 46, 60-64. doi:10.1134/S0020168510010140

44. Demidova, M. G.; Bulavchenko, A. I.; Alekseev, A. V. Russ. J. Inorg. Chem. 2008, 53, 1446-1454. doi:10.1134/S0036023608090167

45. Cheng, L.; Shao, Q.; Shao, M.; Wei, X.; Wu, Z. J. Phys. Chem. C 2009, 113, 1764-1768. doi:10.1021/jp808907e

46. Liu, J.-K.; Luo, C.-X.; Quan, N.-J. J. Nanopart. Res. 2008, 10, 531-535. doi:10.1007/s11051-007-9277-8

47. Yu, J.; Dai, G.; Cheng, B. J. Phys. Chem. C 2010, 114, 19378-19385. doi:10.1021/jp106324x

48. Zhang, X.; Lei, L. J. Hazard. Mater. 2008, 153, 827-833. doi:10.1016/j.jhazmat.2007.09.052

49. Park, H.; Choi, W.; Hoffmann, M. R. J. Mater. Chem. 2008, 18, 2379-2385. doi:10.1039/b718759a

50. Bagwe, R. P.; Khilar, K. C. Langmuir 1997, 13, 6432-6438. doi:10.1021/la9700681

51. Bagwe, R. P.; Khilar, K. C. Langmuir 2000, 16, 905-910. doi:10.1021/la980248q

52. Bagwe, R. P.; Yang, C.; Hilliard, L. R.; Tan, W. Langmuir 2004, 20, 8336-8342. doi:10.1021/la049137j

53. Xiong, L.; He, T. Chem. Mater. 2006, 18, 2211-2218. doi:10.1021/cm052320t

54. Xu, Z.; Yu, J.; Xiao, W. Chem.-Eur. J. 2013, 19, 9592-9598. doi:10.1002/chem.201300438

55. Xu, Z.; Yu, J.; Liu, G.; Cheng, B.; Zhou, P.; Li, X. Dalton Trans. 2013, 42, 10190-10197. doi:10.1039/c3dt51067k

56. Sing, K. S. W. Pure Appl. Chem. 1982, 54, 2201-2218. doi:10.1351/pac198254112201

57. Sing, K. S. W. Pure Appl. Chem. 1985, 57, 603-619. doi:10.1351/pac198557040603

58. Kruk, M.; Jaroniec, M. Chem. Mater. 2001, 13, 3169-3183. doi:10.1021/cm0101069

59. Jeevanandam, P.; Mulukutla, R. S.; Phillips, M.; Chaudhuri, S.; Erickson, L. E.; Klabunde, K. J. J. Phys. Chem. C 2007, 111, 1912-1918. doi:10.1021/jp066363o

60. Dhara, S.; Giri, P. K. Nanoscale Res. Lett. 2011, 6, 320-326. doi:10.1186/1556-276X-6-320

61. Zhang, H.; Bayne, M.; Fernando, S.; Legg, B.; Zhu, M.; Penn, R. L.; Banfield, J. F. J. Phys. Chem. C 2011, 115, 17704-17710. doi:10.1021/jp205192a

62. Ran, F.; Miao, L.; Tanemura, S.; Tanemura, M.; Cao, Y.; Tanaka, S.; Shibata, N. Mater. Sci. Eng., B 2008, 148, 35-39. doi:10.1016/j.mseb.2007.09.029 
63. Wu, J.-C.; Zheng, J.; Zacherl, C. L.; Wu, P.; Liu, Z.-K.; Xu, R. J. Phys. Chem. C 2011, 115, 19741-19748. doi:10.1021/jp204799q

64. Li, Q.; Meng, H.; Zhou, P.; Zheng, Y.; Wang, J.; Yu, J.; Gong, J. ACS Catal. 2013, 3, 882-889. doi:10.1021/cs4000975

65. Kato, H.; Kobayashi, H.; Kudo, A. J. Phys. Chem. B 2002, 106, 12441-12447. doi:10.1021/jp025974n

66. Santamaría-Pérez, D.; Bandiello, E.; Errandonea, D.; Ruiz-Fuertes, J.; Gomis, O.; Sans, J. A.; Manjón, F. J.; Rodríguez-Hernández, P.; Muñoz, A. J. Phys. Chem. C 2013, 117, 12239-12248. doi:10.1021/jp401524s

67. Jiang, H.-Q.; Endo, H.; Natori, H.; Nagai, M.; Kobayashi, K. Mater. Res. Bull. 2009, 44, 700-706. doi:10.1016/j.materresbull.2008.06.007

68. Yu, J.; Ran, J. Energy Environ. Sci. 2011, 4, 1364-1371. doi:10.1039/COEE00729C

69. Wu, L.; Yu, J. C.; Fu, X. J. Mol. Catal. A: Chem. 2006, 244, 25-32. doi:10.1016/j.molcata.2005.08.047

70. Takizawa, T.; Watanabe, T.; Honda, K. J. Phys. Chem. 1978, 82, 1391-1396. doi:10.1021/j100501a014

71. Ji, K. H.; Jang, D. M.; Cho, Y. J.; Myung, Y.; Kim, H. S.; Kim, Y.; Park, J. J. Phys. Chem. C 2009, 113, 19966-19972. doi:10.1021/jp906476m

72. Hagfeldt, A.; Grätzel, M. Chem. Rev. 1995, 95, 49-68. doi:10.1021/cr00033a003

73. Hoffmann, M. R.; Martin, S. T.; Choi, W.; Bahnemann, D. W. Chem. Rev. 1995, 95, 69-96. doi:10.1021/cr00033a004

74. Lee, H.-S.; Woo, C.-S.; Youn, B.-K.; Kim, S.-Y.; Oh, S.-T.; Sung, Y.-E.; Lee, H.-I. Top. Catal. 2005, 35, 255-260. doi:10.1007/s11244-005-3832-2

75. Wang, P.; Huang, B.; Qin, X.; Zhang, X.; Dai, Y.; Wei, J.; Whangbo, M.-H. Angew. Chem., Int. Ed. 2008, 47, 7931-7993. doi:10.1002/anie.200802483

76. Wang, P.; Huang, B.; Zhang, X.; Qin, X.; Jin, H.; Dai, Y.; Wang, Z.; Wei, J.; Zhan, J.; Wang, S.; Wang, J.; Whangbo, M.-H. Chem.-Eur. J. 2009, 15, 1821-1824. doi:10.1002/chem.200802327

77. Segall, M. D.; Lindan, P. J. D.; Probert, M. J.; Pickard, C. J.; Hasnip, P. J.; Clark, S. J.; Payne, M. C. J. Phys.: Condens. Matter 2002, 14, 2717-2744. doi:10.1088/0953-8984/14/11/301

78. Zhou, P.; Yu, J.; Wang, Y. Appl. Catal., B: Environ. 2013, 142-143, 45-53. doi:10.1016/j.apcatb.2013.04.063

79. Perdew, J. P.; Burke, K.; Ernzerhof, M. Phys. Rev. Lett. 1996, 77, 3865-3868. doi:10.1103/PhysRevLett.77.3865

80. Perdew, J. P.; Wang, Y. Phys. Rev. B 1992, 45, 13244-13249. doi:10.1103/PhysRevB.45.13244

81. Kumazawa, H.; Inoue, M.; Kasuya, T. Ind. Eng. Chem. Res. 2003, 42, 3237-3244. doi:10.1021/ie020723m

82. Yu, J.-G.; Yu, H.-G.; Cheng, B.; Zhao, X.-J.; Yu, J. C.; Ho, W.-K. J. Phys. Chem. B 2003, 107, 13871-13879. doi:10.1021/jp036158y

83. Yu, J.; Li, Q.; Liu, S.; Jaroniec, M. Chem.-Eur. J. 2013, 19, 2433-2441. doi:10.1002/chem.201202778

\section{License and Terms}

This is an Open Access article under the terms of the Creative Commons Attribution License

(http://creativecommons.org/licenses/by/2.0), which permits unrestricted use, distribution, and reproduction in any medium, provided the original work is properly cited.

The license is subject to the Beilstein Journal of Nanotechnology terms and conditions:

(http://www.beilstein-journals.org/bjnano)

The definitive version of this article is the electronic one which can be found at:

doi:10.3762/bjnano.5.77 